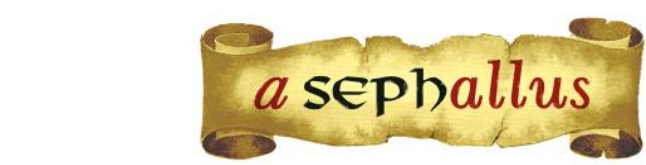

Revista aSEPHallus de Orientação Lacaniana

Núcleo Sephora de Pesquisa sobre o Moderno e o Contemporâneo

ISSN $1809-709 \mathrm{X}$

\title{
Perversão e práticas perversas: contribuições da psicanálise
}

Maria Helena Coelho Martinho

Doutora e Mestre pelo Programa de Pós-Graduação em Psicanálise do Instituto de Psicologia da Universidade do Estado do Rio de Janeiro/UERJ (Rio de Janeiro, Brasil) Professora dos Cursos de Mestrado e Doutorado em Psicanálise, Saúde e Sociedade da Universidade Veiga de Almeida (Rio de Janeiro, Brasil) Professora do Curso de Especialização em Teoria Psicanalítica e Prática Clínico-Institucional e do Curso de Graduação em Psicologia da Universidade Veiga de Almeida (Rio de Janeiro, Brasil) Coordenadora e Supervisora Clínica do Serviço de Psicologia Aplicada (SPA) da Universidade Veiga de Almeida (Rio de Janeiro, Brasil)

Professora e Supervisora Clínica do Curso de Especialização em Psicologia Clínica da Pontifícia Universidade Católica do Rio de Janeiro/PUC-Rio (Rio de Janeiro, Brasil) Psicanalista Membro da Escola de Psicanálise dos Fóruns do Campo Lacaniano/EPFCL-Brasil (Rio de Janeiro, Brasil)

Psicanalista Membro do Colegiado de Formações Clínicas do Campo Lacaniano/EPFCL-Rio de Janeiro (Rio de Janeiro, Brasil)

E-mail: mhmartinho@yahoo.com.br

Maria da Gloria Schwab Sadala Doutora pela Escola de Comunicação da Universidade Federal do Rio de Janeiro/UFRJ (Rio de Janeiro, Brasil) Coordenadora do Programa de Doutorado em Psicanálise, Saúde e Sociedade da Universidade Veiga de

Almeida/UVA (Rio de Janeiro, Brasil)

Coordenadora do Curso de Pós-Graduação em Teoria Psicanalítica e Prática Clínico-institucional da Universidade Veiga de Almeida/UVA (Rio de Janeiro, Brasil)

Professora do Mestrado em Psicanálise, Saúde e Sociedade da Universidade Veiga de Almeida/UVA (Rio de Janeiro, Brasil) Supervisora do Serviço de Psicologia Aplicada do Curso de Graduação em Psicologia da Universidade Veiga de Almeida/UVA (Rio de Janeiro, Brasil)

Professora do Curso de Especialização em Psicologia Clínica da Pontifícia Universidade Católica do Rio de Janeiro/PUC-RJ (Rio de Janeiro, Brasil) Psicanalista Membro da Escola de Psicanálise dos Fóruns do Campo Lacaniano/EPFCL-Brasil (Rio de Janeiro, Brasil) Psicanalista Membro do Colegiado de Formações Clínicas do Campo Lacaniano/EPFCL-Rio de Janeiro (Rio de Janeiro, Brasil)

E-mail: gloriasadala@gmail.com

Resumo: O cinema, os jornais e as redes sociais expõem frequentemente diversas práticas ditas perversas, tais como: pedofilia, homossexualidade, travestismo, sadomasoquismo. Este artigo se propõe a tomar algumas dessas práticas focalizadas pela sétima arte para analisá-las segundo as proposições teóricas e clínicas de duas áreas de saber: a psiquiatria e a psicanálise. O estudo investiga divergências entre ambas as áreas e examina contrastes entre as conjecturas feitas pela psiquiatria e as formulações psicanalíticas a partir das descobertas de Freud sobre a sexualidade humana. O texto conclui que as ditas práticas perversas desvelam o caráter universal da sexualidade humana - perversa polimorfa - que se manifesta de forma singular em cada sujeito de acordo com a sua própria história e a sua forma de gozo. Para a psicanálise, a estrutura perversa nunca será diagnosticada a partir das práticas perversas, pois só poderá ser identificada com base na posição do sujeito diante do seu parceiro.

Palavras-chave: perversão; práticas perversas; psicanálise; psiquiatria.

Perversion et pratiques perverses: contributions de la psychanalyse

Le cinéma, les journal et les réseaux sociaux exposent souvent plusieurs pratiques dites perverses comme la pédophilie, l'homosexualité, le travestisme, le sadomasochisme. Cet article vise à prendre certaines de ces pratiques, mises en évidence par le septième art, et les analyser selon les propositions théoriques et cliniques de deux domaines du savoir: la psychiatrie et la psychanalyse. L'étude examine les divergences entre les deux domaines et examine les contrastes entre les conjectures faites par la psychiatrie et les formulations 
psychanalytiques des découvertes de Freud sur la sexualité humaine. Le texte conclue que les pratiques perverses dévoilent le caractère universel de la sexualité humaine - pervers polymorphe - qui se manifeste d'une manière unique à chaque sujet en fonction de leur propre histoire et leur mode de jouissance. Pour la psychanalyse, la structure perverse ne sera jamais diagnostiqué de pratiques pervereses, il ne peut être identifié comme pratiques perverses, mais en raison de la position du sujet en face de votre partenaire.

Mots-clés: perversion; pratiques perverses; psychanalyse; psychiatrie.

\section{Perversion and perverse practices: contributions of psychoanalysis}

The film industry, newspapers and social networks often expose various practices called perverse, such as pedophilia, homosexuality, transvestism, sadomasochism. This article aims to take some of theses practices focused on by the seventh art and analyze them according to the theoretical and clinical propositions of two areas of knowledge: psychiatry and psychoanalysis. The study investigates differences between both areas and examines contrasts between the conjectures made by psychiatry and psychoanalytic formulations from the discoveries of Freud about human sexuality. The text concludes that practices called perverse unveil the universal character of human sexuality - polymorphous perverse - that manifests itself in a unique way in each subject according to their own history and their way of enjoyment. For psychoanalysis the perverse structure will never be diagnosed from practices, it can only be identified based on the subject's position in front of their partner.

Key-words: perversion; perverse practices; psychoanalysis; psychiatry. 


\title{
Perversão e práticas perversas: contribuições da psicanálise
}

\author{
Maria Helena Coelho Martinho \& Maria da Gloria Schwab Sadala
}

\section{Introdução}

Este artigo se propõe a tomar algumas práticas ditas perversas, tais como: pedofilia, homossexualidade, travestismo, sadomasoquismo, expostas frequentemente pelo cinema, jornais, redes sociais, destacando-as em alguns filmes para analisá-las segundo as proposições teóricas e clínicas da psicanálise. $O$ estudo investiga divergências entre duas áreas de saber: a psiquiatria e a psicanálise; examina contrastes entre as conjecturas feitas pela psiquiatria e as formulações psicanalíticas a partir das descobertas de Freud sobre a sexualidade humana.

Tomaremos aqui apenas a sétima arte para ilustrar as práticas ditas perversas, uma vez que encontramos inúmeros filmes retratando-as. Em Má educação (Madri, 1980), dirigido por Almodóvar, o protagonista Enrique Goded, um cineasta que passa por um bloqueio criativo, tem problemas em elaborar um novo projeto, quando um ator que procura trabalho aproxima-se dele identificando-se como seu amigo mais íntimo e também o primeiro amor de sua vida, quando ainda eram garotos e estudavam no mesmo colégio. Goded recebe do antigo amigo um roteiro intitulado "A Visita" que foi elaborado com experiências homossexuais que ambos tiveram e com situações de pedofilia vividas pelo Padre Manolo professor deles de literatura.

O filme A professora de piano (2002), dirigido por Michel Haneke, exibe vários jogos perversos. A protagonista Reika Kohut trabalha como professora de piano no Conservatório de Viena. Ela não bebe nem fuma, vive em casa com sua mãe aos quarenta anos de idade. Mas, quando não está dando aulas, Erika frequenta cinemas pornôs e peepshows, em busca de excitação. Erika inicia um relacionamento com um de seus alunos com quem realiza vários jogos ditos perversos.

Em Uma nova amiga (2014) dirigido por François Ozon, Claire e Laura eram duas amigas inseparáveis desde a infância. O filme desvela segredos. O marido de Laura é um crossdreser, Laura e a sua amiga vivem uma relação homossexual durante a infância e adolescência.

O filme $A$ garota dinamarquesa (2016), dirigido por Tom Hooper, baseado no livro homônimo de David Ebershoff, mostra a história de amor real entre as pintoras dinamarquesas Lili Elbe e Gerda Gottieb. Lili foi uma das primeiras mulheres a passar por uma cirurgia de transgenitalização.

Estes são apenas alguns exemplos que extraímos da arte cinematográfica para interrogar: por que razão as práticas ditas perversas são tão frequentemente retratadas pelos cineastas? Por que os jornais, as revistas e as redes sociais, ou seja, a mídia em geral instiga o público ao debate sobre questões tão polêmicas?

Este tema nos impulsiona a indagar sobre estas ditas perversões. Sabemos das contribuições recíprocas que ocorreram entre a psiquiatria e a psicanálise ao longo do tempo. Mas, em relação a este tema haveria alguma divergência entre estas duas áreas de saber? Qual é a posição da psiquiatria contemporânea em relação às práticas mencionadas? 


\section{Como a psiquiatria contemporânea analisa as práticas perversas?}

A referência fundamental sobre as perversões era a Psicopatia sexualis (1886), de KrafftEbing, um verdadeiro tratado, no qual o autor coloca as perversões "do lado da esterilidade, do prazer e da patologia, conjugando a morte, o gozo e a doença numa oposição radical à sexualidade normal, onde devem encontrar-se a saúde, um quantum módico de prazer e a reprodução" (Lanterilaura, 1994, p. 37). Krafft-Ebing ressalta a dicotomia que alinha, de um lado, a norma e a reprodução, e de outro, a esterilidade e a doença, delimitando o campo específico das perversões sexuais às satisfações eróticas cujo objetivo não era a preservação da espécie.

A nosografia psiquiátrica atual com suas séries de DSM (Manual de Diagnóstico e Estatística da Associação Norte-Americana de Psiquiatria) e CID (Classificação Internacional de Doenças) classifica a perversão como um "Transtorno da Sexualidade". Embora o termo perversão ainda seja utilizado pelo jurídico foi, entretanto, definitivamente banido dos diagnósticos psiquiátricos, tendo deixado em seu lugar as "Parafilias", classificadas na categoria dos "Transtornos Sexuais", seção que contém também as "Disfunções Sexuais" e os "Transtornos da Identidade de Gênero".

Fazem parte da classificação de "Parafilias" os seguintes diagnósticos do DSM IV: exibicionismo (exposição dos genitais), fetichismo (uso de objetos inanimados), frotteurismo (tocar e esfregar-se em uma pessoa sem o seu consentimento), pedofilia (foco em crianças pré-púberes), masoquismo sexual (ser humilhado ou sofrer), sadismo sexual (infligir humilhação ou sofrimento), fetichismo transvéstico (vestir-se com roupas do sexo oposto), voyeurismo (observar atividades sexuais).

Estão incluídos na categoria "Parafilia sem outra especificação": escatologia telefônica (telefonemas obscenos), necrofilia (atração sexual por cadáver), parcialismo (foco exclusivo em uma parte do corpo), zoofilia (atração sexual por animais), coprofilia (excitação sexual relativa ao contato com fezes do parceiro sexual), clismafilia (excitação sexual causada de preferência ou exclusivamente por enemas) e urofilia (excitação associada ao ato de urinar ou receber o jato urinário do parceiro).

De acordo com o DSM IV as "Características Diagnósticas" essenciais de uma parafilia consistem "de fantasias, anseios sexuais ou comportamentos recorrentes, intensos e sexualmente excitantes, em geral envolvendo:

1) objetos não-humanos;

2) sofrimento ou humilhação, próprios ou do parceiro, ou

3) crianças ou outras pessoas sem o seu consentimento, tudo isso ocorrendo num período mínimo de 6 meses (critério A)".

A classificação psiquiátrica nos induz a pensar que a homossexualidade, a transexualidade, a pedofilia, os estupros, o sadomasoquismo, por exemplo, são patologias que requerem cuidados psiquiátricos. As classificações descritas nestes manuais diagnósticos se contrapõem ao que a teoria 
psicanalítica revela sobre as estruturas clínicas: neurose, psicose, perversão. Os DSM e CID constituem-se, no nível da fenomenologia, dos transtornos, naquilo que se observa dos sintomas. Ao contrário, a psicanálise não pode abrir mão da noção de estrutura clínica, pois, se assim o fizesse, estaria desconsiderando o inconsciente freudiano e deixando, portanto, de lado, a descoberta da origem sexual e da determinação significante que está inscrita no inconsciente.

\section{As concepções psicanalíticas sobre a perversão}

É importante lembrar que as referências à perversão aparecem na obra de Freud no período germinal de sua elaboração teórica (1886-1904), antes mesmo da publicação dos "Três ensaios sobre a teoria da sexualidade" (1905). Verifica-se que, até o final de 1897, Freud lançou sobre a perversão o mesmo olhar moralista empregado pela psiquiatria clássica do século XIX, considerando determinadas práticas sexuais como degeneradas ou bestiais, desvios em relação à norma sexual e social, ou seja, Freud corroborou com os argumentos que estavam em voga evitando, inicialmente, possíveis conflitos com a comunidade científica de sua época. Um enunciado lançado por Freud em sua correspondência com Fliess, na "Carta 55" (6 de abril de 1897, p. 281), indica que naquela época Freud se referia à perversão como animalidade: "As perversões, por regra geral, desembocam em zoofilia e têm caráter animal". Este ponto de vista sobre a perversão se mantém até Freud revelar a Fliess na "Carta 69" suas dúvidas acerca da perversão e da teoria da etiologia traumática da neurose, teoria que ele havia sustentado durante os cinco anos anteriores. A partir dessa data, Freud deixa de acreditar que em todos os casos de neurose, inclusive no seu próprio, o pai haveria de ser um tarado, um perverso, o culpado pela sedução da criança, pois se fosse realmente assim, a perversão seria incomensuravelmente mais frequente que a histeria. Com esta descoberta, Freud conclui que no inconsciente "não existe um sinal de realidade de forma que não se pode distinguir a verdade da ficção investida com afeto. A fantasia sexual se relaciona sempre ao tema dos pais" (Freud, 1987, p. 301).

Em uma carta de 15 de outubro de 1897 ("Carta 71"), Freud anuncia a descoberta da importância que pode adquirir para o sujeito, o drama, a tragédia de Sófocles: "uma única ideia de valor generalizado abriu-se para mim. Eu encontrei em mim o enamoramento pela mãe e o ciúme contra o pai e os considero agora como um acontecimento generalizado da primeira infância [...] Cada um dos ouvintes foi uma vez, em semente, e na fantasia, um Édipo" (Freud, 1897, p. 307). Assim, no final de 1897, Freud coloca a pedra fundamental do que mais tarde seria chamado complexo de Édipo. Ele já não pôde mais acreditar num trauma vivido na realidade, tal como contavam as suas pacientes, mas levantou a hipótese de uma fantasia que teria o mesmo conteúdo do trauma real. A fantasia sexual que se apodera regularmente do tema dos pais é a origem da neurose.

Vê-se que os elementos da teoria de Freud sobre a sexualidade então já estavam presentes em sua obra, mas a pedra angular foi descoberta somente em 21 de setembro de 1897, quando ele 
passa da teoria do trauma ou da sedução à teoria da fantasia; momento em que também descarta o julgamento moralista, higienista, que vinha utilizando em relação à perversão. Entretanto, as incertezas de Freud provavelmente só se dissiparam com a índole dinâmica das moções pulsionais sexuais presentes na infância, e com a comprovação plena de que as fantasias podem operar com toda a força das vivências reais.

É interessante notar que, dois anos após ter descoberto a fantasia sexual nos neuróticos, Freud escreve uma carta a Fliess, mais precisamente em 9 de dezembro de 1899 ("Carta 125"). Nessa carta consagrada justamente à escolha da neurose - que se pode traduzir como a escolha da estrutura clínica - Freud já colocara em série, de uma forma impressionante, a neurose (histeria e neurose obsessiva), a psicose e a perversão. Isso não seria um prenúncio de que vinte e oito anos mais tarde, em 1927, ele estaria de fato distinguindo a perversão da neurose e da psicose?

A histeria (e sua variante, a neurose obsessiva) é aloerótica, sua via principal é a identificação com a pessoa amada. A paranoia é um assalto da corrente autoerótica e um retorno a uma situação da infância, pela ruptura das identificações e despedaçamento do eu. O que corresponde à perversão seria a chamada 'loucura idiopática'. As relações particulares do autoerotismo com o eu originário iluminariam bem o caráter desta neurose. (Freud, 1899, p. 322)

É bem verdade que no final desse enunciado Freud se refere à perversão como se ela fosse uma neurose. Contudo, não se pode esquecer que quatro anos antes, em 24 de janeiro de 1895, no

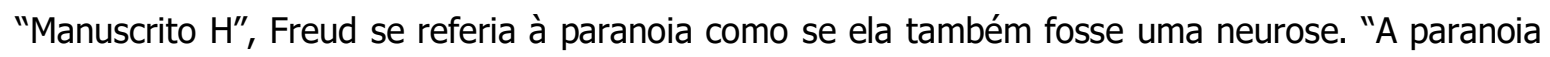
crônica em sua forma clássica é um modo patológico de defesa, como a histeria, a neurose obsessiva e a confusão alucinatória" (Freud, 1895, p. 247). Sendo assim, nos autorizamos a considerar que encontramos em 1899, já delineado, um ponto de vista inteiramente novo em relação à perversão, embora ele ainda não tivesse sido claramente desenvolvido.

Quando escreveu o caso clínico de Dora, no começo de 1901, publicado em 1905 com o título "Fragmento da análise de um caso de histeria" (1905[1901]), Freud já estava completamente distante das suas teorias de degenerescência de 1888, treze anos já haviam se passado e Freud já havia estabelecido firmemente os alinhamentos principais de sua teoria da sexualidade. No caso Dora, Freud é enfático ao afirmar que é preciso que se possa falar sem indignação das chamadas perversões sexuais, dessas transgressões da função sexual tanto no âmbito do corpo quanto no do objeto sexual. Ele questiona com toda clareza os limites do "normal" e do patológico: "A incerteza no tocante aos limites do que deve ser chamado de vida sexual normal, quando levamos em conta raças e épocas diferentes, deve por si mesmo bastar para esfriar o ardor do apaixonado" (Freud, 1905[1901], p. 45). 
Como vanguardista que sempre demonstrou ser, desde 1897, Freud segue numa via completamente contrária aos cientistas de sua época. Refuta com clareza todas as teorias degenerativas admitidas pela psiquiatria clássica para o determinismo das perversões e considera que cada um de nós em nossa própria vida sexual transgride os limites do que julga normal. "Tampouco deveríamos duvidar que a mais depreciável, para nós, dessas perversões, o amor sexual entre homens, em um povo que tanto nos avantajava em cultura como foi o dos gregos não só era tolerada senão que se atribuíam importantes funções sociais" (Freud, 1905[1901], p. 45). Freud retira a homossexualidade do contexto patológico no qual a psiquiatria daquela época a havia inserido. Além disso, reconhece que as forças impulsoras para a formação de sintomas histéricos não provêm apenas da sexualidade normal recalcada, senão também das moções perversas inconscientes. Sendo assim, "se em pessoas sãs se pode comprovar sem esforço acerca dos germes normais da perversão, mais evidentes nos neuróticos, nos faz esperar também uma mais forte disposição homossexual na constituição dos últimos" (Freud, 1905[1901], p. 54). Freud verifica que tanto na neurose desencadeada quanto naquela que não se desencadeou se comprova a perversão sexual e a homossexualidade. A bissexualidade está presente em todos. Essa tese de Freud sobre a perversão será central daí por diante. Levantamos a hipótese de que Freud vai, gradativamente, ao longo de sua obra, demonstrar que a sexualidade de todo ser humano é perversa.

Senão vejamos, no "Manuscrito K. As neuroses de defesa" (1896a, p. 260), Freud já havia descrito as neuroses como "aberrações patológicas de estados afetivos psíquicos normais". Nove anos depois, nos "Três ensaios..." (1905), Freud irá dizer que a uniformidade da configuração do quadro normal nos engana, pois nos faz correr o risco de deixar passar despercebido o fato de que a pulsão está meramente soldada a seu objeto. Isso quer dizer que a aberração é que diz a verdade do quadro normal que é capaz de nos enganar.

No caso Dora, cinco anos depois da publicação do "Manuscrito K", Freud declara com todas as letras que as perversões não são nem bestialidades nem degenerações e afirma categoricamente que todos os neuróticos são pessoas com inclinações perversas, antecipando assim as futuras descobertas reveladas nos "Três ensaios..." sobre o polimorfismo da sexualidade humana.

Cada um de nós, em sua própria vida sexual, ora nisto, ora naquilo, transgride um pouco os estreitos limites do que se julga normal. As perversões não são nem bestialidades nem degenerações no sentido patético da palavra. São desenvolvimento de germes, contidos todos eles na disposição sexual indiferenciada da criança, cuja sufocação ou cuja volta (Wendung) fazia metas mais elevadas, asexuais - sua sublimação -, estão destinadas a proporcionar a força motriz de um bom número de nossos logros culturais [...] Todos os neuróticos são pessoas com inclinações perversas muito marcadas, mas recalcadas e tornadas inconscientes no curso do desenvolvimento. Por isso suas fantasias inconscientes exibem idêntico 
conteúdo que as ações que se tem documentado nos perversos [...]. As neuroses são, por assim dizer, o negativo das perversões. (Freud, 1905[1901], p. 45, grifo nosso)

No caso Dora, Freud enuncia mais uma vez a célebre fórmula: "A neurose é o negativo da perversão". Dizemos "mais uma vez" porque essa frase já havia sido formulada antes, nesses mesmos termos, em uma carta a Fliess de 24 de janeiro de 1897 ("Carta 57") (Freud, 1897, p. 284): "Nas perversões, cujo negativo é a histeria...". Além disso, ela já estava implícita na carta de 6 de dezembro de 1896 ("Carta 52") (Freud, 1896, p. 279): "Às vezes, há na mesma pessoa histérica uma metamorfose: perversa na idade em que tem a plenitude de suas forças, e logo histérica, a partir de um período de angústia; então a histeria não é na verdade uma sexualidade desautorizada (ablehnen), mas uma perversão desautorizada". Essa fórmula será reeditada também em "Psicopatologia da vida cotidiana":

As fantasias dos histéricos acerca dos maus tratos sexuais e cruéis, que a análise tem que fazer conscientes, coincidem às vezes mesmo em detalhes, com as queixas dos que sofrem de paranoia persecutória. E é curioso, mas não ininteligível, que encontremos conteúdo idêntico em forma de realidade objetiva nas encenações que os perversos fazem para satisfazer as suas tendências. (Freud, 1901, p. 248)

Encontramos a célebre fórmula nos "Três ensaios sobre a teoria da sexualidade" (1905a), e em "As fantasias histéricas e sua relação com a bissexualidade" (1908a). Contudo, foi no caso Dora que Freud fez a observação fundamental que serve como um divisor de águas em relação às teorias degenerativas e evolutivas, classicamente admitidas na época para o determinismo das perversões. Momento em que a referência fundamental sobre as perversões era a Psicopatia sexualis (1886), de Krafft-Ebing como mencionado anteriormente.

Pode-se verificar que Freud, desde o início de suas elaborações, ao contrário daquelas teorias, começa a conceber a perversão como uma posição do sujeito. A tese que afirma que os neuróticos têm tendências perversas recalcadas, daí por diante central, será retomada quatro anos mais tarde nos "Três ensaios sobre a teoria da sexualidade" (1905a), para explicitar que:

Os sintomas de modo algum nascem unicamente à custa da pulsão sexual chamada normal (não, ao menos, de maneira exclusiva ou predominante), sendo que constituem a expressão convertida de pulsões que se designariam perversas (no sentido mais lato) puderam exteriorizar-se diretamente, sem desvio para a consciência, em desígnios da fantasia e em ações. Portanto, os sintomas se formam 
em parte à custa de uma sexualidade anormal; a neurose é, por assim dizer, 0 negativo da perversão. (Freud, 1905a, p. 150)

No seu texto príncipes de 1905, "Três ensaios sobre a teoria da sexualidade", as inovadoras teorias freudianas sobre a sexualidade humana e a introdução do conceito de pulsão nestas teorias fazem certamente dos "Três ensaios..." um divisor de águas, um primeiro tempo na economia psíquica da perversão na obra de Freud. À medida que Freud avança no conceito da pulsão sexual, ele vai configurando a perversão como uma predisposição da sexualidade. Ele chama atenção para o fato de que Krafft-Ebing e Havelock Ellis qualificam de perversas, na verdade são todas as práticas de gozo, todas as modalidades de gozo que não sejam as do coito heterossexual com a finalidade de reprodução, ou seja, todos os gozos não localizados na zona genital.

Nos títulos dos textos de Freud observa-se uma extrema eloquência: praticamente a direção do texto fica estabelecida por uma cuidadosa leitura do título. Em "As aberrações sexuais", o primeiro dos seus "Três ensaios...", o próprio título já indica que o texto introduz uma denúncia da impropriedade dos cientistas da época quanto ao emprego da palavra perversão ao atribuir-Ihe o caráter de um signo patológico ou degenerativo, tal como fizeram a respeito da homossexualidade. Freud subverte aqui mais uma vez a clínica médica de sua época rechaçando radicalmente este ponto de vista.

A maioria das transgressões é um ingrediente da vida sexual que raramente falta nas pessoas sãs. Se as circunstâncias os favorecem, também a pessoa normal pode substituir durante todo um período a meta sexual normal por uma perversão desta classe ou dar-lhe um lugar junto aquela. Em nenhuma pessoa sã faltará algum complemento da meta sexual normal que poderia chamar-se perverso, e esta universalidade basta por si só para mostrar quão inadequado é usar de forma reprovatória o nome de perversão. No campo da vida sexual, justamente, se tropeça com dificuldades particulares, em verdades insolúveis por ora, quando se pretende traçar um limite tangente entre o que é mera variação dentro da amplitude fisiológica e os sintomas patológicos. (Freud, 1905a, p. 146)

Freud destaca a universalidade perversa da sexualidade humana. Contudo, ele se vê diante de um impasse: se a perversão é universal, os atos perversos assombrosos podem ser considerados "normais"? Freud alega que algumas destas perversões que se afastam do "normal", são aquelas em que a pulsão sexual executa "assombrosas operações", tais como, lamber excrementos, abusar de cadáveres. 
Se a perversão não se apresenta junto ao normal (meta sexual e objeto) quando circunstâncias favoráveis a promovem e outras desfavoráveis impedem o normal, senão que suplanta (verdrängen) e substitui ao normal em todas as circunstâncias, consideramos legítimo quase sempre julgá-la como um sintoma patológico; vemos este último, portanto, na exclusividade e na fixação da perversão. (Freud, 1905a, pp. 146-147)

O extraordinário polimorfismo das manifestações da sexualidade no homem, o fato de que seus desvios se encontram em todos os seres humanos, dificulta, para Freud, a tarefa de fazer uma definição mais precisa da perversão. Por essa razão, ele formula além de certas manifestações incontestavelmente patológicas, como por exemplo, a coprofilia e a necrofilia, que só se pode distinguir a perversão da normalidade porque a perversão se caracteriza por uma fixação do desvio quanto ao objeto e pela exclusividade da prática quanto ao desvio com relação à meta.

Vale lembrar que, quanto aos desvios em relação ao objeto sexual - a escolha do mesmo sexo, de crianças e animais como objetos sexuais -, Freud verifica que "na vida psíquica inconsciente de todos os neuróticos (sem exceção) se encontram moções pulsionais de inversão, de fixação da libido em pessoas do mesmo sexo [...] a inclinação inconsciente à inversão nunca falta e, em particular, presta os maiores serviços ao esclarecimento da histeria masculina" (Freud, 1905a, p. 151).

Quanto aos desvios em relação à meta sexual - as transgressões anatômicas referentes às zonas do corpo destinadas à união sexual (boca e ânus utilizados como órgão sexual e o fetichismo como substituto do objeto sexual); e as fixações de metas sexuais provisórias (tocar, olhar, sadismo e masoquismo) -, Freud observa que "no inconsciente dos neuróticos podem se pesquisar como formadores de sintoma, todas as inclinações à transgressão anatômica; entre elas, com particular frequência e intensidade, as que reclamam para as mucosas oral e anal o papel dos genitais" (Freud, 1905a, p. 151).

Dessa forma, verifica que as pulsões parciais desempenham um papel importante entre os formadores de sintomas das neuroses: a pulsão do prazer do olhar e da exibição, e a pulsão de crueldade, configurada ativa e passivamente. Toda perversão ativa é acompanhada por sua contraparte passiva. Quem no inconsciente é exibicionista, é ao mesmo tempo voyeur, quem padece das consequências do recalque de moções sádicas recebe outro suplemento aos seus sintomas desde as fontes de uma inclinação masoquista.

Em um caso de neurose mais definido, raras vezes se encontra uma só destas pulsões perversas: na maioria das vezes encontramos um grande número delas e, por regra geral traços de todas. Todavia, a intensidade de cada pulsão singular é 
independente do desenvolvimento das outras. Também neste ponto o estudo das perversões 'positivas'nos proporciona a exata contrapartida. (Freud, 1905a, p. 152)

Levantamos a hipótese de que Freud parece aqui predizer uma diferenciação entre os "traços perversos" encontrados em todos os neuróticos e a estrutura perversa, na medida em que se refere à "perversão positiva" como a "exata contrapartida da neurose". A pesquisa de Freud sobre as "moções perversas enquanto formadoras de sintoma nas neuroses" elevou extraordinariamente o número de homens aos quais poderia qualificar-se de perversos. "Assim, a extraordinária difusão das perversões nos força a supor que tampouco a disposição para elas é uma rara particularidade, mas que tem que formar parte da constituição julgada normal" (Freud, 1905a, p. 156).

Freud agora oferece esta resolução para o dilema que se impõe entre o "normal" e o "patológico": a perversão é "inata em todos os homens".

Na base das perversões tem em todos os casos algo inato, mas algo que é inato em todos os seres humanos, por mais que sua intensidade flutue e possa com o tempo ser realizada por influências vitais. Trata-se de umas raízes inatas da pulsão sexual, dadas na constituição mesma, que em uma série de casos (perversões) se desenvolvem até converterem-se nos portadores reais da atividade sexual, outras vezes experimentam uma sufocação (recalque) insuficiente, a raiz do qual podem atrair para si mediante um caminho, em qualidade de sintomas patológicos, uma parte considerável de energia sexual, na medida em que os casos mais favorecidos, situados entre ambos extremos, permitem, graças a uma restrição eficaz e a algum outro procedimento, a gênese da vida sexual normal. (Freud, 1905a, p. 156, grifo nosso)

Aqui Freud ainda não havia identificado o mecanismo de defesa próprio da estrutura perversa. Entretanto, ele parece prenunciar uma importante distinção entre a neurose e a estrutura perversa, quando destaca o mecanismo de defesa da neurose ("recalque") e o retorno do recalcado ("sintomas") distinguindo-os de outro mecanismo diverso que retornaria para o sujeito "nos portadores reais da atividade sexual (perversos)" (Freud, 1905a, p. 156). Já estaria Freud aqui indicando o fetiche como mecanismo de defesa da perversão?

Freud abala toda a concepção científica daquela época sobre as perversões ao declarar que a perversão é "inata em todos os homens" e, além disso, ela é encontrada não somente nos adultos, mas também nas crianças. No segundo dos "Três ensaios...", "A sexualidade infantil", Freud evidencia que a criança não é aquele ser ingênuo e sem malícia como se fazia crer frequentemente naquela época, mas a criança tem uma sexualidade e, além do mais, esta sexualidade é perversa. $O$ estudo da sexualidade infantil fornece ensinamentos preciosos para a compreensão da sexualidade 
no adulto. Freud destaca como caráter mais chamativo da prática sexual da criança, o fato de que a pulsão não está dirigida a outra pessoa, ou seja, ela se satisfaz no próprio corpo, ela é "autoerótica"1. Observa também que a sexualidade infantil apresenta outra característica fundamental, a criança sob a influência da sedução converte-se em um "perverso-polimorfo, sendo levado a praticar todas as transgressões possíveis" (Freud, 1905, p. 173). A criança gosta de se exibir e de ficar olhando, ou seja, ela é exibicionista e voyeurista. Gosta de chupar, de se masturbar e tem atividades anais e sadomasoquistas. $O$ que se encontra na sexualidade infantil aparece nos perversos na idade adulta, nas alucinações e delírios psicóticos, no inconsciente dos neuróticos e nos jogos sexuais de todos. Nos Três ensaios, Freud reconhece que "a disposição às perversões é a disposição originária e universal da pulsão sexual dos seres humanos e a partir dela, a consequência de alterações orgânicas e inibições psíquicas, se desenvolve no curso da maturação a conduta sexual normal" (Freud, 1905, p. 211).

Os "Três ensaios..." marcam assim a descoberta revolucionária acerca da sexualidade humana. A partir de Freud, a perversão passa a ser vista pela psicanálise como o paradigma da sexualidade humana e não mais como uma patologia. Ao inscrever o sexual ali onde ele era impensável - no infantil e no inconsciente -, Freud desvela a influência determinante no ser humano de uma ordem libidinal inconsciente. $\mathrm{Na}$ medida em que definiu a sexualidade infantil como essencialmente polimorfa, aberrante, o encanto de uma pretensa inocência da criança foi quebrado.

Em O Seminário, livro 11: os quatro conceitos fundamentais da psicanálise (1964), Lacan comenta que desde os "Três ensaios...", Freud pôde colocar a sexualidade como polimorfa e aberrante.

Em relação à instância da sexualidade, todos os sujeitos estão em igualdade, desde a criança até o adulto - que eles só têm a ver com aquilo que, da sexualidade, passa para as redes da constituição subjetiva, para as redes significantes - que a sexualidade só se realiza pela operação das pulsões parciais, parciais em relação à finalidade biológica da sexualidade. (Lacan, 1964b, p. 167)

Segundo a leitura lacaniana de Freud, a pulsão é o conceito psicanalítico que se revela inseparável da questão sobre o inconsciente. Lacan observa que é preciso considerar atentamente os textos de Freud. "O precioso dos textos de Freud é que à maneira dos bons arqueólogos, ele deixa o trabalho de escavação no lugar - de modo que mesmo se inacabada, podemos saber o que querem dizer objetos desenterrados" (Lacan, 1964b, p. 172). Já em O Seminário, livro 1: os escritos técnicos de Freud (1953-1954), Lacan havia retomado o trabalho arqueológico de Freud em seus Três ensaios para interrogar: "O que é a perversão?". Responde a essa questão reafirmando as postulações de Freud de 1905, "perversão não é simplesmente aberração em relação a critérios sociais, anomalia contrária aos bons costumes, ou atipia em relação a critérios naturais, isto é, que 
ela derroga mais ou menos a finalidade reprodutora da conjugação sexual. Ela é outra coisa na sua estrutura mesma" (Lacan, 1953-1954, p. 252).

\section{Considerações finais}

As pesquisas desenvolvidas no âmbito da psiquiatria e da psicanálise nos levaram a concluir que aquilo que os jornais, as revistas, o cinema, a literatura, a mídia de forma geral, propõem como práticas perversas, desvelam o caráter universal da sexualidade humana - perversa polimorfa - que se manifesta de forma singular em cada sujeito de acordo com a sua própria história e a sua forma de gozo.

O encaminhamento desta pesquisa baseada na psicanálise freudiana e lacaniana nos conduziu às seguintes conclusões: a estrutura perversa faz série com as estruturas clínicas neurose e psicose; ao contrário do que muitos possam imaginar, a estrutura perversa não deve ser confundida com as práticas perversas; o diagnóstico clínico diferencial estrutural deverá privilegiar a posição do sujeito diante do seu parceiro, ao invés de considerar apenas os fenômenos, as modalidades de gozo.

\section{Nota}

${ }^{1}$ Freud (1905a, p. 164) toma este termo de Havelock Ellis (1898). Vale lembrar que para Lacan as pulsões parciais estão, desde a origem, enlaçadas com o Outro da palavra e da linguagem. $\mathrm{Na}$ "Conferência em Genebra sobre o sintoma", Lacan diz que vai discordar do próprio Freud, pois "o autoerotismo é o que há de mais hetero" (Lacan, 1975, p. 10). A pulsão supõe o grande Outro (A) e o pequeno outro (a), a pulsão não é autoerótica, pois vai buscar no Outro um objeto parcial. Na verdade, no "Projeto de psicologia" (Freud, 1895) o próprio Freud já havia defendido a tese de que a sexualidade é introduzida no sujeito a partir do Outro, na medida em que observa a primeira experiência de satisfação.

\section{Referências Bibliográficas}

Freud, S. (2004). Proyecto de psicología. Obras completas (Vol. 1). Buenos Aires: Amorrortu (Trabalho original publicado em 1895a).

Freud, S. (2004). Manuscrito H. Paranoia. Fragmentos de la correspondência con Fliess. Obras completas (Vol. 1). Buenos Aires: Amorrortu (Trabalho original publicado em 1895b).

Freud, S. (2004). Manuscrito K. Las neurosis de defensa. (Un cuento de Navidad). Fragmentos de la correspondência con Fliess. Obras completas (Vol. 1). Buenos Aires: Amorrortu (Trabalho original publicado em 1896a).

Freud, S. (2004). Carta 52. Fragmentos de la correspondência con Fliess. Obras completas (Vol. 1). Buenos Aires: Amorrortu (Trabalho original publicado em 1896b).

Freud, S. (2005). Sumario de los trabajos científicos del docente adscrito Dr. Sigm. Freud. Obras completas (Vol. 3). Buenos Aires: Amorrortu (Trabalho original publicado em 1897a). 
Freud, S. (2004). Carta 55. Fragmentos de la correspondência con Fliess. Obras completas (Vol. 1). Buenos Aires: Amorrortu (Trabalho original publicado em 1897b).

Freud, S. (2004). Carta 57. Fragmentos de la correspondência con Fliess. Obras completas (Vol. 1). Buenos Aires: Amorrortu (Trabalho original publicado em 1897c).

Freud, S. (2004). Manuscrito N (Anotações III). Fragmentos de la correspondência con Fliess. Obras completas (Vol. 1). Buenos Aires: Amorrortu (Trabalho original publicado em 1897d).

Freud, S. (2004). Carta 69. Fragmentos de la correspondência con Fliess. Obras completas (Vol. 1). Buenos Aires: Amorrortu (Trabalho original publicado em 1897e).

Freud, S. (2004). Carta 71. Fragmentos de la correspondência con Fliess. Obras completas (Vol. 1). Buenos Aires: Amorrortu (Trabalho original publicado em 1897f).

Freud, S. (2004). Carta 125. Fragmentos de la correspondência con Fliess. Obras completas (Vol. 1). Buenos Aires: Amorrortu (Trabalho original publicado em 1899).

Freud, S. (2004). Psicopatología de La vida cotidiana. Obras completas (Vol. 6). Buenos Aires: Amorrortu (Trabalho original publicado em 1901).

Freud, S. (2005). Fragmento de análisis de un caso de histeria. Obras completas (Vol. 7). Buenos Aires: Amorrortu (Trabalho original publicado em 1905[1901]).

Freud, S. (2005). Tres ensayos de teoría sexual. Obras completas (Vol. 7). Buenos Aires: Amorrortu (Trabalho original publicado em 1905).

Freud, S. (2003). Las fantasías histéricas y su relación con la bisexualidad. Obras completas (Vol. 9). Buenos Aires: Amorrortu (Trabalho original publicado em 1908).

Lacan, J. (1986). O seminário, livro 1: os escritos técnicos de Freud. Rio de Janeiro: Zahar (Trabalho original publicado em 1953-1954).

Lacan, J. (1990). O seminário, livro 11: os quatro conceitos fundamentais da psicanálise. Rio de Janeiro: Zahar (Trabalho original publicado em 1964).

Lacan, J. (1988). Conferência de Genebra sobre o sintoma. Intervenciones e textos. Buenos Aires: Manantial (Trabalho original publicado em 1975).

Lanteri-Laura, G. (1994). Leitura das perversões: história de sua apropriação médica. Rio de Janeiro: Zahar.

Citacão/Citation: Martinho, M. H. C. \& Sadala, M. G. S. (mai. a out. 2016). Perversão e práticas perversas: contribuições da psicanálise. Revista aSEPHallus de Orientação Lacaniana, 11(22), 94-107. Disponível em www.isepol.com/asephallus. doi: 10.17852/1809-709x.2019v11n22p94-107.

Editor do artigo: Tania Coelho dos Santos.

Recebido/Received: 20/08/2016 / 08/20/2016.

Aceito/Accepted: 11/09/2016 / 09/11/2016.

Copyright: (c) 2013 Associação Núcleo Sephora de Pesquisa sobre o moderno e o contemporâneo. Este é um artigo de livre acesso, que permite uso irrestrito, distribuição e reprodução em qualquer meio, desde que o autor e a fonte sejam citados/This is an open-access article, which permites unrestricted use, distribution, and reproduction in any medium, provided the author and source are credited. 